\title{
Effects of drugs on the effectiveness of conditioned stimuli
}

\author{
JOHN R. DeWITT and HAROLD C. NIELSON \\ University of Utah, Salt Lake City, Utah 84112
}

\begin{abstract}
Drugged and nondrugged cats were trained to give the same foreleg-flexion response (CR) to two different conditioned stimuli (CSs): (1) a 1,000-Hz tone and (2) a direct electrical stimulation of either the caudate nucleus or the hippocampus. Pentobarbital and other depressant drugs had consistent, differential effects on performance of CRs to the two different CSs. Cats drugged with pentobarbital learned to respond to the brain stimulation, but seemingly could not learn to respond to the tone unless they previously had acquired CRs to the brain stimulation. Furthermore, for all but one of the nondrugged-trained cats, doses of pentobarbital, chloral hydrate, meprobamate, or chlordiazepoxide were found that abolished CRs to tone but left the same $\mathrm{CRs}$ to brain stimulation intact. Implications of these results are discussed with respect to the drug-stimulus hypothesis and other current explanations of state-dependent learning.
\end{abstract}

State-dependent learning, which is produced by a large number of centrally acting drugs, is a phenomenon that has been reported for a wide variety of animal species and tasks (for reviews that include species, tasks, and drugs, see Overton, 1971a, 1971b). While there are several theoretical explanations of state-dependent learning, one of the earliest, and the one that is probably the most often proposed, is the "drug-stimulus" hypothesis (Brown, Feldman, \& Moore, 1968; Otis, 1964; Overton, 1971b). This hypothesis is that drugs produce stimuli that become part of the stimulus complex of a particular learning situation. When drugged-state changes occur, they are hypothesized to produce changes in the stimulus components of the learning situation. Hence, a stimulus generalization gradient between the drugged and the nondrugged state is thought to be established, with the steepness of the gradient determined by the size of the drug dose that produced the drugged state. Thus, response failures associated with state changes represent failures of stimulus generalization. This theory stems from an analogy of the response control exerted by peripheral stimuli, and it is attractively simple.

The evidence advanced in support of the "drugstimulus" hypothesis is that animals can be trained to discriminate among different doses of the same drug and among doses of different drugs. However, it does not necessarily follow, from the conclusion that drugged states can be discriminated, that drug

This research was supported by the U.S. Army Medical Research and Development Command Contract DADA-17-73-C3029. Requests for reprints should be addressed to John R. DeWitt, Department of Psychology, University of Utah, Salt Lake City, Utah 84112. discrimination is the basis for state-dependent learning. There are important differences in the methodologies for establishing drug discrimination and statedependent learning. In general, smaller drug doses are used in investigations of drug discrimination than in investigations of state-dependent learning. Additionally, a discrimination paradigm is always used in studies of drug discrimination, whereas factorial designs are most often used for state-dependent learning. Barry (1974) has presented additional arguments for maintaining the distinction between the two phenomena. He points out that drug discrimination develops gradually as a consequence of differential reinforcement, whereas state-dependent learning is a response decrement that appears suddenly, frequently following a single trial. Barry also emphasizes that drug discrimination implies that the animal has the capability of selecting either response under either drug condition. While this appears to be the case for drug-discrimination studies, it does not appear to be true for state-dependent learning. Pusakulich and Nielson (1976) found that drugged rats could not learn a place response, whereas nondrugged rats could. Furthermore, they found that once an animal had adopted a particular mode of responding in one state, it was restricted in the mode of responding that it could adopt in an alternative state. Their rats clearly did not have the freedom to select either response in either state.

There were two major objectives of the experiments reported here. The first of these was to investigate more directly whether there is a restriction in the use of peripheral stimuli as cues in the drugged state, as implied by Pusakulich and Nielson (1976), that would interfere with the animal's ability to acquire either response in either drugged condition, as found in drug- 
discrimination studies. Our second objective was to provide a further test of the "drug-stimulus" hypothesis of state-dependent learning. The "drug-stimulus" hypothesis is that drugs produce stimuli that become part of the stimulus context of the learning situation and come to exercise control over the response, and that response failure when the drug is removed is a failure of stimulus generalization. If this is true, that is, if the drug-produced stimulus that comes to exercise response control, then there should be no differential effects of a drug dose upon a conditioned response (CR) elicited by either of two different conditioned stimuli (CSs). We report here that drugs do differentially affect a CR elicited by two different CSs, and we reject the "drug-stimulus" hypothesis of state-dependent learning.

That drugs may differentially influence the effectiveness of different CSs, in eliciting a CR, is suggested by Rutledge and Doty (1955). They found that a given dose of chlorpromazine would abolish a forelegflexion CR established to a tone CS, but would not abolish the CR if the CS was direct electrical stimulation of the brain. We tested the drug-stimulus hypothesis of state-dependent learning, using the method of Rutledge and Doty. Pusakulich and Nielson (1972) have shown that this method can be used to produce state-dependent CRs. Additionally, our test was first conducted with pentobarbital to maximize any drugstimulus effects. Pentobarbital is said to exercise "strong" stimulus control over the response (Overton, 1971b), whereas chlorpromazine, the drug used by Rutledge and Doty, is said to exercise only "weak" stimulus control over the response (Overton, 1971b).

\section{EXPERIMENT 1}

\section{Method}

Subjects. The subjects were cats of mixed age and sex, weighing between 2.7 and $4.7 \mathrm{~kg}$. Throughout the course of the experiment, they were housed individually and given ad-lib access to food and water.

Surgical procedure. Each cat was anesthetized with sodium pentobarbital $(40 \mathrm{mg} / \mathrm{kg}$, ip) and implanted with bipolar electrodes aimed at the caudate nucleus $(A=16.5, L=11.0, \mathrm{~V}=5.0)$ or the hippocampus $(\mathrm{A}=2.5, \mathrm{~L}=11.0, \mathrm{~V}=3.0)$ using coordinates obtained from the atlas of Snider and Niemer (1961). The electrodes were two strands of enameled 28-ga nichrome wire, bonded with Insulx, with stimulating tips separated vertically by $1 \mathrm{~mm}$. The electrode leads were attached to the terminals of a nine-plug Winchester ( $\mathrm{S}-4 \mathrm{~J})$ female socket fixed to the cat's skull by dental acrylic. Following the operation, 2 weeks were allowed before avoidance training was begun.

Training procedure. Descriptions of the training procedure are available elsewhere (Doty, Rutledge, \& Larsen, 1956; Nielson, Knight, \& Porter, 1962; Pusakulich \& Nielson, 1972). Briefly, each cat was habituated to a hammock that restricted gross movement but allowed free movement of the head and limbs. During avoidance training, a copper cuff was attached to the cat's right foreleg, which was placed on a copper grid. The unconditioned stimulus (US) was delivered through the grid and the cuff, but the cat could break this circuit by making a foreleg-flexion conditioned response (CR) and thus avoid the US. The cats were given avoidance training to two different CSs, one delivered peripherally and one delivered through the implanted electrodes. One peripheral CS was a $1,000-\mathrm{Hz}$ tone, delivered for $2 \mathrm{sec}$ at an intensity of $90 \mathrm{~dB}$ as measured at the cat's ear. The other peripheral CS was a flashing light, delivered from a Grass Model PS-2 photic stimulator, that flashed at $1 \mathrm{~Hz}$ for $2 \mathrm{sec}$. An intermediate light intensity was used for the first 2,000 trials, and the maximum intensity was used for an additional 2,000 trials. The flashing light was located directly in front of the cat, $2 \mathrm{ft}$ from its face. The other CS was $2 \mathrm{sec}$ of electrical stimulation $(100-\mathrm{Hz}$, biphasic, square-wave pulses, $1 \mathrm{msec}$ duration, at intensities of .01 to $1.0 \mathrm{~mA}$ ) delivered through caudatal or hippocampal electrodes from a Nuclear Chicago constant current stimulator. Stimulation delivered through a particular electrode was used as a CS only if it did not elicit forced movements. When such movements were elicited, the CS was delivered through another electrode that did not elicit them. The US was a .2-sec footshock (100-Hz, monophasic, square-wave pulses) delivered from a Grass S4G stimulator. The US intensity was adjusted individually for each cat so as to produce an unconditional response that completely cleared the grid upon which the cat's forepaw had been placed.

A daily training session consisted of 25 trials. The intertrial interval was $35 \mathrm{sec}$, except that at least five trials were presented aperiodically to prevent temporal conditioning. The criterion for learning was reached when 15 avoidances were made in a daily session of 25 trials. When a cat had reached criterion with one CS, either the tone or the brain stimulation, training was given with the other CS until criterion was again reached. When criterion for learning had been met with both CSs, conditioning thresholds to the brain stimulation were determined. Thresholds were defined as the CS intensity that elicited CRs on $50 \%$ of the CS presentations. The CS intensity first was lowered, in blocks of five trials, until CRs were no longer elicited and then raised in blocks of five trials until the cat was again responding. The procedure was repeated until stable values were obtained. One additional condition of the training procedure was that some cats were drugged with $12.5 \mathrm{mg} / \mathrm{kg}$ (ip) pentobarbital prior to each training session. Training of these drugged-trained cats began as soon as they had regained their righting reflexes sufficiently to maintain an upright posture. Two of these drugged-trained cats were trained first with direct electrical stimulation of the brain as the CS and then to the tone CS, but with a drug dosage level of 10 rather than $12.5 \mathrm{mg} / \mathrm{kg}$. The remaining drugged-trained cats were given their first training to either the tone or the light CS.

All drugged and nondrugged-trained cats that successfully completed training were tested for response generalization while drugged with one of several doses of pentobarbital $(0,5.0,7.5,10.0$, or $12.5 \mathrm{mg} / \mathrm{kg}$; ip). Nondrugged-trained cats received the doses in ascending order of size; drugged-trained cats received the doses in the opposite order. During tests with tone, the intensity of the CS was increased by $5 \mathrm{~dB}$ at intervals of five trials from the training intensity of $90 \mathrm{~dB}$ to $105 \mathrm{~dB}$ as measured at the cat's ear. In tests with the brain stimulation, conditioning thresholds were determined any time that CRs could be elicited on over $60 \%$ of the trials. If CRs could not be elicited at intensities used during training, the intensity was increased until CRs or forced movements were elicited or a value of $1.0 \mathrm{~mA}$ was reached.

\section{Results}

The results of training are summarized in Table 1. Nondrugged cats had no difficulty in acquiring CRs to either a tone or to direct electrical stimulation of the brain. The numbers of trials to criterion are consistent with the results previously found with this method for nondrugged-trained cats (Doty, Rutledge, \& Larsen, 1956; Nielson, Knight, \& Porter, 1962; Pusakulich \& Nielson, 1972). On the other hand, cats trained while drugged with $12.5 \mathrm{mg} / \mathrm{kg}$ could acquire 
Table 1

Trials to Criterion of Cats Trained While Drugged (D) and Nondrugged (ND)

\begin{tabular}{ccccc} 
& \multicolumn{4}{c}{ Order of Training and Trials to Criterion } \\
\cline { 2 - 5 } Cat & CS $_{1}$ & Trials & CS $_{2}$ & Trials \\
\hline ND-1 & SH & 300 & T & 25 \\
ND-2 & SH & 315 & T & 25 \\
ND-3 & T & 295 & SH & 50 \\
ND-4 & T & 350 & SH & 75 \\
ND-5 & SC & & T & \\
ND-6 & SC & & T & \\
D-1 & SH & 525 & T & 300 \\
D-2 & SH & 480 & T & 455 \\
D-3 & & & T & $1465^{*}$ \\
D-4 & & & T & $1480^{*}$ \\
D-5 & & & L & $4000^{*}$ \\
D-6 & & & L & $4000^{*}$ \\
D-7 & & & L & $4000^{*}$ \\
\hline
\end{tabular}

Note $-S H=$ stimulation of hippocampus, $S C=$ stimulation of caudate; $T=$ tone, $L=$ light. $\quad$ *Training was discontinued after the tabled number of trials.

CRs only if the CS was direct electrical stimulation of the brain. The results for the drugged-trained cats, with their first training to peripheral CSs (either tone or light), were very clear. These cats could not be trained, when drugged, to give CRs. After we had given over 4,000 trials to the light CS and the animals still showed no sign of conditioning, we discontinued training. We gave up more easily when the CS was the tone. By that time, we had the training failure to the light and had given nearly five times as many trials to the tone CS as was necessary to train the nondrugged cats. We have concluded that drugged cats cannot be trained to give this foreleg flexion CR to either the tone or light CS unless they were first trained to give the CR to central stimulation (Cats D-1, D-2).

Table 2 summarizes the performance of individual cats after they had received different doses of pentobarbital. The doses of pentobarbital that abolished the CRs are somewhat different for each nondruggedtrained cat, but, in every instance, the CRs established to the peripheral CS were abolished at lower doses than were the CRs established to direct electrical stimulation of the brain. Thus, for any given cat, some dose of pentobarbital abolished the CR established to tone but left the same CR established to central stimulation intact. This differential effect occurred whether tests were given within a single session or on separate occasions. That the percent CRs elicited by the tone CS is unrelated to its intensity is shown in Figure 1. This figure shows the mean percent CRs made by nondrugged-trained cats tested while they

Table 2

Effects of Change of Drugged Conditions Present During Training on Responses Established to Tone and to Electrical Brain Stimulation and Upon Conditioning Thresholds of the Brain Stimulation of Drugged-Trained (D) and Nondrugged-Trained (ND) Cats

\begin{tabular}{|c|c|c|c|c|c|c|c|}
\hline \multirow[b]{2}{*}{ Cat } & \multirow[b]{2}{*}{ CS } & \multicolumn{6}{|c|}{ Pentobarbital Dose (in Milligrams per Kilogram, ip) } \\
\hline & & Training & 0 & 5 & 7.5 & 10 & 12.5 \\
\hline ND-1 (SH) & $\begin{array}{l}\text { CS Threshold } \\
\text { Percent CRs } \\
\text { Tone-Percent CRs }\end{array}$ & $\begin{array}{r}.150 \\
88 \\
88\end{array}$ & $\begin{array}{r}.150 \\
88 \\
88\end{array}$ & $\begin{array}{l}* \\
0 \\
0\end{array}$ & & & \\
\hline ND-2 (SH) & $\begin{array}{l}\text { CS Threshold } \\
\text { Percent CRs } \\
\text { Tone-Percent CRs }\end{array}$ & $\begin{array}{r}.120 \\
80 \\
75\end{array}$ & $\begin{array}{r}.120 \\
80 \\
75\end{array}$ & $\begin{array}{l}.20 \\
80 \\
70\end{array}$ & $\begin{array}{r}.13 \\
100 \\
5\end{array}$ & $\begin{array}{r}.15 \\
80 \\
0\end{array}$ & $\begin{array}{l}* \\
0\end{array}$ \\
\hline ND-3 (SH) & $\begin{array}{l}\text { CS Threshold } \\
\text { Percent CRs } \\
\text { Tone-Percent CRs }\end{array}$ & $\begin{array}{r}.140 \\
88 \\
90\end{array}$ & $\begin{array}{r}.140 \\
80 \\
55\end{array}$ & $\begin{array}{r}.15 \\
60 \\
5\end{array}$ & $\begin{array}{r}.22 \\
60 \\
0\end{array}$ & $\begin{array}{l}* \\
0 \\
0\end{array}$ & \\
\hline $\mathrm{ND}-4(\mathrm{SH})$ & $\begin{array}{l}\text { CS Threshold } \\
\text { Percent CRs } \\
\text { Tone-Percent CRs }\end{array}$ & $\begin{array}{r}.120 \\
80 \\
88\end{array}$ & $\begin{array}{r}.120 \\
80 \\
88\end{array}$ & $\begin{array}{l}.23 \\
80 \\
80\end{array}$ & $\begin{array}{r}.23 \\
100 \\
20\end{array}$ & $\begin{array}{l}* \\
0 \\
0\end{array}$ & \\
\hline ND-5 (SC) & $\begin{array}{l}\text { CS Threshold } \\
\text { Percent CRs } \\
\text { Tone-Percent CRs }\end{array}$ & $\begin{array}{r}.085 \\
80 \\
75\end{array}$ & $\begin{array}{r}.085 \\
80 \\
75\end{array}$ & $\begin{array}{r}.20 \\
100 \\
45\end{array}$ & $\begin{array}{r}.28 \\
80 \\
0\end{array}$ & $\begin{array}{l}* \\
0\end{array}$ & \\
\hline ND-6 (SC) & $\begin{array}{l}\text { CS Threshold } \\
\text { Percent CRs } \\
\text { Tone-Percent CRs }\end{array}$ & $\begin{array}{r}.050 \\
88 \\
80\end{array}$ & $\begin{array}{r}.050 \\
88 \\
35\end{array}$ & $\begin{array}{r}.11 \\
100 \\
5\end{array}$ & $\begin{array}{r}.14 \\
100 \\
0\end{array}$ & $\begin{array}{r}.10 \\
100 \\
0\end{array}$ & $\begin{array}{l}* \\
0\end{array}$ \\
\hline D-1 (SH) & $\begin{array}{l}\text { CS Threshold } \\
\text { Percent CRs } \\
\text { Tone-Percent CRs }\end{array}$ & $\begin{array}{r}.050 \\
80 \\
84\end{array}$ & $\begin{array}{r}.430 \\
0 \\
95\end{array}$ & $\begin{array}{r}.07 \\
80 \\
95\end{array}$ & $\begin{array}{l}.05 \\
80 \\
95\end{array}$ & $\begin{array}{l}.05 \\
80 \\
85\end{array}$ & $\begin{array}{l}.05 \\
80 \\
85\end{array}$ \\
\hline D-2 (SH) & $\begin{array}{l}\text { CS Threshold } \\
\text { Percent CRs } \\
\text { Tone-Percent CRs }\end{array}$ & $\begin{array}{r}.150 \\
100 \\
80\end{array}$ & $\begin{array}{r}.070 \\
80 \\
50\end{array}$ & $\begin{array}{r}.03 \\
100 \\
80\end{array}$ & $\begin{array}{r}.03 \\
100 \\
100\end{array}$ & $\begin{array}{r}.15 \\
100 \\
80\end{array}$ & $\begin{array}{r}.15 \\
100 \\
80\end{array}$ \\
\hline
\end{tabular}

Note-CS thresholds are given in milliamperes. $S H=$ stimulation of hippocampus, $S C=$ stimulation of caudate.

*Response frequency was too low for thresholds to be determined. 


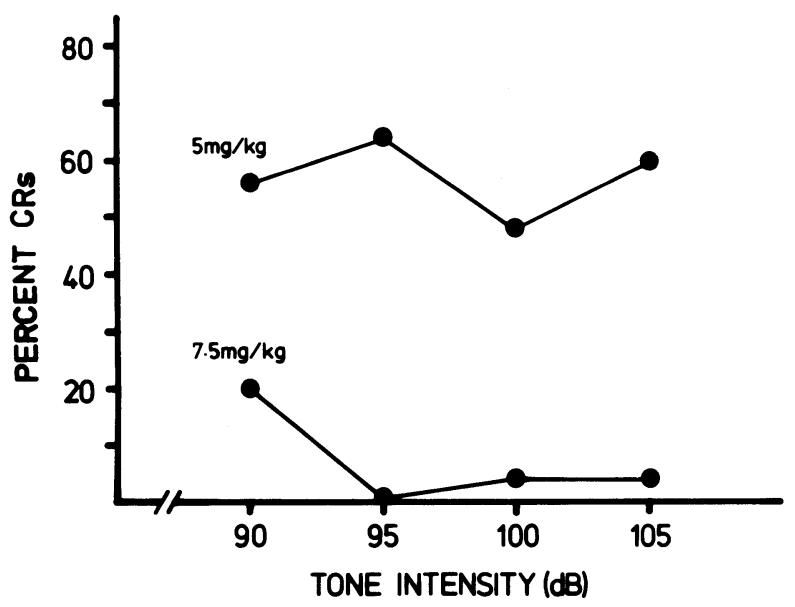

Figure 1. Percent CRs given by nondrugged-trained cats following injections of 5 or $7.5 \mathrm{mg} / \mathrm{kg}$ sodium pentobarbital (ip).

were drugged with 5.0 and $7.5 \mathrm{mg} / \mathrm{kg}$ pentobarbital, across CS intensities from 90 to $105 \mathrm{~dB}$ as measured at the cat's ear. We believe that a tone CS intensity of this magnitude is sufficient to elicit CRs if they can be elicited.

\section{EXPERIMENT 2}

In this second experiment, we determined whether the effects seen in the first experiment were unique to pentobarbital. A variety of sedative hypnotic drugs, including meprobamate, chlordiazepoxide, and chloral hydrate, produce state-dependent learning, perhaps through a common mechanism. Drug-dependent responses established under the influence of any one of these drugs can be supported by the substitution of any of the others (Overton, 1971a). The argument that drug-produced stimuli mediate state-dependent learning could no longer be tenable if, like pentobarbital, these drugs differentially affect CRs to peripheral and central CSs.

\section{Method}

Procedure. Seven cats were implanted and trained according to the procedures described earlier. Two of the cats were implanted with electrodes aimed at the hippocampus, and five were implanted with electrodes aimed at the caudate nucleus. Two of the latter had been used previously in Experiment 1. Cats were all trained while nondrugged. Parameters of the brain stimulation, the tone, and the US were similar to those used earlier.

After reaching criterion for learning with both CSs, cats were tested for retention of responding while drugged with meprobamate $(50,75,100$, and $125 \mathrm{mg} / \mathrm{kg}$; oral), chloral hydrate $(50,75,100$, and $125 \mathrm{mg} / \mathrm{kg}$; oral), and chlordiazepoxide $(7.5,12.5,17.5$, and $22.5 \mathrm{mg} / \mathrm{kg}$; ip). The order in which different drugs were given was randomized for each cat, and doses of each were presented in ascending order of dose. Each dose was given twice. The order of testing with the different CSs was random.

Special testing. After completing all phases of the training and testing for drug effects upon the CRs, these cats were given an additional series of tests to assess the functioning of the peripheral sensory systems. They were drugged with the smallest dose of pentobarbital that abolished their CRs established to both the peripheral and central CSs, and then, instead of being tested in the conditioning apparatus, they were tested for their detection and subsequent pursuit of a white mouse on one occasion or their detection and subsequent avoidance of a dog on another. In tests with mice, cats were placed in an observation box that was $1 \mathrm{~m}$ square with walls $1 \mathrm{~m}$ high, and then were given a mouse. The cat's ability to detect and pursue the mouse for $5 \mathrm{~min}$ was rated either high or low for detection and high or low for pursuit. In the tests with the dog, the cats were placed in the center of a large $(5 \times 5 \mathrm{~m})$ room that had several cabinets and tables that could serve as hiding places. Then, a large, leashed German Shorthair was brought into the room and the cats were rated as to their degree of awareness of the dog by how long it took them to start toward a hiding place.

\section{Results}

Table 3 summarizes the CS thresholds for brain stimulation and the response rates each cat gave with the two CSs. Again, as in the first experiment, for no cat were CRs elicited by subcortical stimulation abolished at a lower dose of any drug than were CRs elicited by the tone CS. In fact, with only one cat, ND-6, were the CRs established to tone and the brain stimulation affected to the same extent, and this was true only with meprobamate. Cat ND-9 was refractory to chlordiazepoxide, and CRs to both tone and hippocampal stimulation were still present with a dose of $22.5 \mathrm{mg} / \mathrm{kg}$. It seems clear, then, that all of the drugs have effects similar to those produced by pentobarbital.

The special testing of these cats, with doses of pentobarbital that abolished all CRs, indicated to us that their sensory abilities to detect a mouse and pursue it or to detect a dog and avoid it were unimpaired even though their attempts to capture prey or flee from a predator were uncoordinated. These cats were not blind or deaf, but they could not perform CRs.

\section{DISCUSSION}

There are several reasons for interpreting these results within the framework of state-dependent learning. First, there is the demonstration by Pusakulich and Nielson (1972) that foreleg flexion CRs elicited by central stimulation are state dependent. Thus, we interpret the drugged-state induced loss of the CRs in the nondrugged trained cats as a state-dependent loss. Similarly, we feel that the CRs elicited by the central stimulation for the drugged-trained cats (D-1 and D-2) could have been demonstrated to be state dependent had we not given them the additional training to the tone CS at the lower drug dosages. Indeed, the centrally elicited CRs of one drugged-trained cat (D-1) actually were state dependent despite the training to tone. Furthermore, we do not feel that, because we did not independently demonstrate statedependent learning with CRs established to peripheral cues, there is a restriction in our ability to interpret 
Table 3

Brain Stimulation Thresholds and Percent CRs Given to Tone and Brain Stimulation by Cats as a Function of Drug Dose

\begin{tabular}{|c|c|c|c|c|c|c|c|c|c|c|c|c|c|c|c|c|}
\hline \multirow[b]{3}{*}{ Cat } & \multirow[b]{3}{*}{$\mathrm{CS}$} & \multicolumn{15}{|c|}{ Dose (in Milligrams per Kilogram) } \\
\hline & & \multicolumn{5}{|c|}{ Chlordiazepoxide (ip) } & \multicolumn{5}{|c|}{ Meprobamate (Oral) } & \multicolumn{5}{|c|}{ Chloral Hydrate (Oral) } \\
\hline & & 0 & 7.5 & 12.5 & 17.5 & 22.5 & 0 & 50 & 75 & 100 & 125 & 0 & 50 & 75 & 100 & 125 \\
\hline $\mathrm{ND}-4(\mathrm{SC})$ & $\begin{array}{l}\text { CR Threshold } \\
\text { Percent CRs } \\
\text { Tone-Percent CRs }\end{array}$ & $\begin{array}{l}.09 \\
80 \\
75\end{array}$ & $\begin{array}{l}.09 \\
80 \\
14\end{array}$ & $\begin{array}{r}.13 \\
80 \\
29\end{array}$ & $\begin{array}{r}.16 \\
60 \\
3\end{array}$ & $\begin{array}{r}.18 \\
60 \\
3\end{array}$ & $\begin{array}{l}.09 \\
80 \\
75\end{array}$ & $\begin{array}{r}.13 \\
100 \\
20\end{array}$ & $\begin{array}{r}.180 \\
60 \\
11\end{array}$ & $\begin{array}{r}.24 \\
70 \\
3\end{array}$ & & $\begin{array}{l}.09 \\
80 \\
75\end{array}$ & $\begin{array}{r}.20 \\
100 \\
14\end{array}$ & $\begin{array}{r}.25 \\
60 \\
0\end{array}$ & & \\
\hline ND-5 (SC) & $\begin{array}{l}\text { CR Threshold } \\
\text { Percent CRs } \\
\text { Tone-Percent CRs }\end{array}$ & $\begin{array}{l}.05 \\
88 \\
80\end{array}$ & $\begin{array}{l}.06 \\
70 \\
77\end{array}$ & $\begin{array}{r}.07 \\
80 \\
0\end{array}$ & $\begin{array}{r}.09 \\
80 \\
0\end{array}$ & & $\begin{array}{l}.05 \\
88 \\
80\end{array}$ & $\begin{array}{l}.07 \\
70 \\
77\end{array}$ & $\begin{array}{r}.075 \\
80 \\
6\end{array}$ & $\begin{array}{r}.07 \\
100 \\
0\end{array}$ & & $\begin{array}{r}.05 \\
88 \\
80\end{array}$ & $\begin{array}{r}.05 \\
80 \\
34\end{array}$ & $\begin{array}{r}.05 \\
100 \\
5\end{array}$ & $\begin{array}{r}.05 \\
90 \\
0\end{array}$ & $\begin{array}{l}* \\
0 \\
0\end{array}$ \\
\hline ND-6 (SC) & $\begin{array}{l}\text { CR Threshold } \\
\text { Percent CRs } \\
\text { Tone-Percent CRs }\end{array}$ & $\begin{array}{r}.15 \\
85 \\
85\end{array}$ & $\begin{array}{l}.15 \\
60 \\
71\end{array}$ & $\begin{array}{l}* * \\
* *\end{array}$ & & & $\begin{array}{r}.15 \\
85 \\
85\end{array}$ & $\begin{array}{r}.15 \\
80 \\
71\end{array}$ & $\begin{array}{r}.180 \\
100 \\
25\end{array}$ & $\begin{array}{l}.45 \\
70 \\
49\end{array}$ & * & $\begin{array}{r}.15 \\
85 \\
85\end{array}$ & $\begin{array}{l}.16 \\
90 \\
28\end{array}$ & $\begin{array}{r}.19 \\
60 \\
20\end{array}$ & $\begin{array}{r}.40 \\
60 \\
5\end{array}$ & $\begin{array}{r}.42 \\
60 \\
0\end{array}$ \\
\hline ND-7 (SC) & $\begin{array}{l}\text { CR Threshold } \\
\text { Percent CRs } \\
\text { Tone-Percent CRs }\end{array}$ & $\begin{array}{l}.22 \\
68 \\
83\end{array}$ & $\begin{array}{l}.28 \\
80 \\
80\end{array}$ & $\begin{array}{l}.34 \\
60 \\
31\end{array}$ & $\begin{array}{l}.38 \\
70 \\
11\end{array}$ & $\begin{array}{r}.47 \\
80 \\
0\end{array}$ & & & & & & & & & & \\
\hline ND-8 (SC) & $\begin{array}{l}\text { CR Threshold } \\
\text { Percent CRs } \\
\text { Tone-Percent CRs }\end{array}$ & $\begin{array}{r}.08 \\
88 \\
80\end{array}$ & $\begin{array}{l}.11 \\
70 \\
11\end{array}$ & $\begin{array}{l}* * \\
* *\end{array}$ & & & $\begin{array}{r}.08 \\
88 \\
80\end{array}$ & $\begin{array}{l}.14 \\
60 \\
57\end{array}$ & $\begin{array}{r}.180 \\
80 \\
43\end{array}$ & $\begin{array}{r}.17 \\
100 \\
6\end{array}$ & & $\begin{array}{l}.08 \\
88 \\
80\end{array}$ & $\begin{array}{r}.15 \\
80 \\
42\end{array}$ & $\begin{array}{r}.23 \\
60 \\
26\end{array}$ & $\begin{array}{r}.15 \\
60 \\
0\end{array}$ & 0 \\
\hline ND-9 (SH) & $\begin{array}{l}\text { CR Threshold } \\
\text { Percent CRs } \\
\text { Tone-Percent CRs }\end{array}$ & $\begin{array}{l}.04 \\
82 \\
94\end{array}$ & $\begin{array}{l}07 \\
60 \\
86\end{array}$ & $\begin{array}{l}.11 \\
60 \\
60\end{array}$ & $\begin{array}{l}.28 \\
90 \\
46\end{array}$ & $\begin{array}{l}.28 \\
60 \\
54\end{array}$ & $\begin{array}{l}.04 \\
82 \\
94\end{array}$ & $\begin{array}{l}.06 \\
60 \\
89\end{array}$ & $\begin{array}{r}.080 \\
60 \\
68\end{array}$ & $\begin{array}{r}.09 \\
60 \\
3\end{array}$ & $\begin{array}{r}.16 \\
70 \\
0\end{array}$ & $\begin{array}{r}.04 \\
82 \\
94\end{array}$ & $\begin{array}{r}.07 \\
60 \\
94\end{array}$ & $\begin{array}{l}.10 \\
90 \\
69\end{array}$ & $\begin{array}{r}.23 \\
100 \\
34\end{array}$ & $\begin{array}{r}.26 \\
60 \\
3\end{array}$ \\
\hline ND-10 (SH) & $\begin{array}{l}\text { CR Threshold } \\
\text { Percent CRs } \\
\text { Tone-Percent CRs }\end{array}$ & $\begin{array}{r}.06 \\
82 \\
73\end{array}$ & $\begin{array}{r}.13 \\
70 \\
0\end{array}$ & $\begin{array}{r}.16 \\
60 \\
14\end{array}$ & $\begin{array}{r}* \\
10 \\
0\end{array}$ & & $\begin{array}{r}.06 \\
82 \\
73\end{array}$ & $\begin{array}{r}.12 \\
60 \\
6\end{array}$ & $\begin{array}{r}.110 \\
70 \\
0\end{array}$ & $\begin{array}{r}.13 \\
60 \\
0\end{array}$ & & $\begin{array}{r}.06 \\
82 \\
73\end{array}$ & $\begin{array}{r}.10 \\
80 \\
63\end{array}$ & $\begin{array}{r}.28 \\
60 \\
3\end{array}$ & $\begin{array}{r}* \\
10 \\
0\end{array}$ & \\
\hline
\end{tabular}

Note-CS thresholds are given in milliamperes. $S H=$ stimulation of hippocampus, $S C=$ stimulation of caudate.

${ }^{*}$ Cat did not give enough responses to determine a threshold.

**Cat showed extreme distress when dosed with chlordiazepoxide and could not be tested in hammock.

these results since the drugged cats could not acquire the CRs to these cues. The failure to acquire the CRs to the tone CS was not due to motor impairment, because the same CR was elicited by central stimulation. Rather, we feel that the inability of cats to acquire the CR to peripheral CS describes an important aspect of state-dependent learning-namely, a restriction in the animal's use of peripheral stimulation as cues for learning.

A comment should be made about the acquisition of the CR to the tone CS for Cats D-1 and D-2 while drugged with $10 \mathrm{mg} / \mathrm{kg}$ pentobarbital. We had anticipated, from the previous results of Rutledge and Doty (1955), that there might be differential effects of drugs on CRs elicited by the different CSs. However, we did not anticipate that the cats drugged with $12.5 \mathrm{mg} / \mathrm{kg}$ pentobarbital would be completely unable to acquire the CRs to peripheral CSs. Thus, when Cats D-1 and D-2 acquired the CR to central stimulation while drugged, we elected to determine whether they could then acquire the CR to the tone CS as $10 \mathrm{mg} / \mathrm{kg}$. This dose was larger than that required to abolish the CRs of the nondrugged-trained cats but lower than the $12.5-\mathrm{mg} / \mathrm{kg}$ dose that produced acquisition failure to the peripheral CS. Furthermore, it was within the range of doses $(10$ to $12.5 \mathrm{mg} / \mathrm{kg}$ ) that Pusakulich and Nielson had set as the boundary be- tween drugged and nondrugged states. We thought that, should these cats fail to acquire the CR to a peripheral CS, we would be able to set the boundary between the drugged (pentobarbital) and nondrugged states at $10 \mathrm{mg} / \mathrm{kg}$ or lower. Since they did acquire the CR to the tone CS while drugged with $10 \mathrm{mg} / \mathrm{kg}$, we are not certain what the dose boundaries for the pentobarbital state are. However, Cats D-1 and D-2 required approximately 20 times as many trials to acquire the tone CR while drugged with $10 \mathrm{mg} / \mathrm{kg}$ pentobarbital as did the nondrugged-trained cats (ND-1 and ND-2) that were conditioned in the same order to the two different CSs. Perhaps because it took 20 times as many trials to transfer the CR from the central CS to the peripheral CS for D-1 and D-2 than for ND-1 and ND-2, we have the subjective impression that D-1 and D-2 would not have acquired the CR to the tone CS if they had not first been trained to respond to the central CS while drugged. We do not know this to be true, but we believe the point is not worth pursuing since it would probably require an enormous number of trials for several animals, and the question of boundary doses for the drugged state does not now loom as a critical question to be answered.

The results from these experiments show: (1) that pentobarbital in doses of $12.5 \mathrm{mg} / \mathrm{kg}$ restricts the 
ability of cats to acquire an avoidance CR, if the CS is either a tone or light, and if the cats have not previously acquired the $C R$ to electrical stimulation of the central nervous system, as the CS, while they were drugged; (2) that there are doses of pentobarbital, chlordiazepoxide, meprobamate, and chloral hydrate that abolish CRs elicited by a peripheral CS and leave the same CR intact if it is established to central stimulation; and (3) that drugs abolished the nondruggedtrained cats' CRs, but they do not produce any identifiable impairment of a cat's ability to detect mice or dogs.

We believe that the inability of the drugged-trained cats to acquire the CR to a peripheral CS, while they did to a centrally delivered CS (our data and Pusakulich $\&$ Nielson, 1972), demonstrates that the drugged cats do not have the option of making either response in either state. The second finding, that CRs established to the peripheral CS are abolished at a given drug level but the same CR established to central stimulation is intact, is contrary to the "drug-stimulus" hypothesis. This hypothesis states that it is the stimulus property of a drug that controls responses. It could be argued that, as the drug dosages increase, the saliency of the "drug-stimulus" increases until it finally overwhelms the CS and the CR is lost. However, there is no a priori reason for it to overwhelm the peripheral CS first. Besides, we regard a tone of $105 \mathrm{~dB}$ at the cat's ear to be a fairly strong stimulus. Both of our first two findings lead us to reject the "drug-stimulus" hypothesis of state-dependent learning. Rather, we argue that drugs given in doses sufficient to produce statedependent learning restrict the responsiveness of animals to sensory stimulation and limit the kinds of stimuli to which they will respond.

The results of some earlier studies are consistent with the results reported here. In addition to the restriction of the use of cues reported by Pusakulich and Nielson (1976), Weiskrantz and his co-workers (Gross \& Weiskrantz, 1961; Weiskrantz \& Baltzer, 1965) also report differential drug effects on learned behaviors. They trained nondrugged monkeys, in visual and auditory discrimination and delayed response tasks, and then tested for the retention of responding when the monkeys were drugged with meprobamate. The drug interfered with the performance of the visual and auditory discriminations, but left the performance of the delayed response intact. More recently, Bliss (1974) also has found that visual discriminations are affected more by pentobarbital than are response discriminations. Finally, we now attribute the reduction of exploratory and curiosity behaviors following drug administration to a drug-produced reduction in responsiveness to environmental stimulation (Barry, Wagner, \& Miller, 1962; Bloch \& Silva, 1969; Sachs, 1967).

Our third finding shows that drugs that produce state-dependent learning restrict an animal's respon- siveness to some, but not all, peripheral stimulation. Our cats were not blind or deaf, and they attempted to catch mice and avoid dogs. Similarly, drugged rats will eat (Gill \& Nielson, 1978) and may attempt to mate (Jacobs \& Farel, 1971). This apparent discrepancy between the findings that drugged animals are limited in the use of some kinds of peripheral stimulation and not in the use of others can be resolved by making a distinction between "hard-wired" and "soft-wired" behaviors. By "hard-wired" behaviors, we mean those that can be regarded as instinctual and that have components whose central representations may be genetically determined. In contrast, "soft-wired" behaviors are those that have their central representations established by learning. The findings of Schmidt and Apfelbach (1977) illustrate this distinction. They studied the effects of drugs on both an appetitive CR established to a $1,000-\mathrm{Hz}$ tone and on the mousecatching ability of the ferret. Chlorpromazine (which Rutledge and Doty, 1955, found to differentially affect CRs to tone and to central stimulation) completely abolished the CR established to tone, but only slightly modified the ferret's prey catching, and actually improved both its orientation toward the prey and the placement of bites. Other drugs tested, haloperidol and clozapine, affected different components of the ferret's prey-catching behavior, and, once again, completely abolished the appetitive CRs. This led Schmidt and Apfelbach to argue that different components of the prey-catching behavior have different central representations. Thus, we argue that those sensory-motor integrations whose central representations are established by learning, such as those mediating the avoidance CR we describe here and the appetitive CR described by Schmidt and Apfelbach, are "soft-wired" and are more easily disrupted by drugs that produce state-dependent learning than are those sensory-motor integrations whose central representations are "hard-wired" or can be considered to be instinctual. Overall, we believe that there is a continuum of behavior from "soft-wired" to "hardwired" that is based on the ease with which behaviors are disrupted by drugs. In order of "hardness" of wiring, we tentatively list: (1) CRs recently acquired in discrimination tasks, although, through overtraining, such responses can become more resistant to drugs (Bliss, 1974); (2) responsiveness to environmental stimuli as measured in tasks that measure exploratory or curiosity behaviors; (3) responsiveness to peripheral stimulation when it is used as a CS to signal shock; (4) response discriminations and response sequence learning; and (5) responsiveness to "natural" prey or predators. Such a continuum emphasizes that it is neither the sensory nor motor system alone that is affected by drugs. Rather, it is the functional connections or the sensory-motor integration between them that is disrupted. As we have argued previously, it is this effect that is responsible for drug-induced loss 
of CRs and the production of state-dependent learning (Gill \& Nielson, 1978; Pusakulich \& Nielson, 1976). We believe that the state-dependent loss of the response results from the disruption of the sensory-motor integration controlling the response. We suggested (Gill $\&$ Nielson, 1978) that the state-dependent disruption of behavior is analogous to the concept of sensory neglect that Teitelbaum and his colleagues advanced to explain the deficit following lateral hypothalamic lesions (Marshall, Turner, \& Teitelbaum, 1971; Wolgin, Cytawa, \& Teitelbaum, 1976). That brain lesions can produce deficits resembling state-dependent learning has been shown recently by Modrow, Petroff, and Bliss (1978).

Recently, Colpaert (1978) joined Barry (1974) in arguing for a distinction between state-dependent learning and drug discrimination. He suggested that drug-produced cues should be "thought of as discriminative stimuli which control behavior in much the same way as external stimuli," while "states of an organism can be thought of as distinct levels at which cognitive and emotional functioning can be organized within the organism." We agree that drugged-state learning is functionally different from nondrugged-state learning. Drugged-state learning has been described as more primitive (Sachs, 1967), and we believe that drugged rats do not utilize sensory cues and appear to be limited to the learning of responses or response sequences (Pusakulich \& Nielson, 1976). Moreover, when the components of a "hardwired" sensory-motor integration-which usually are left intact after drug administration-do become state dependent, the deficit is characterized as a deficit of motivation (Gill \& Nielson, 1978). The responses most restricted by drugs, in terms of both acquisition and performance, would appear to be those "softwired" behaviors that must be guided by sensory discriminations and that have not been overtrained. Thus, we argue that "drug-stimulus" effects are not the basis for state-dependent learning. States should be considered as influencing the organization of behaviors.

\section{REFERENCES}

Barry, H., III. Classification of drugs according to the discriminable effects in rats. Federation Proceedings, 1974, 33, 1814-1824.

Barry, H., Wagner, A. R., \& Miller, N. E. Effects of alcohol and amobarbital on performance inhibited by experimental extinction. Journal of Comparative and Physiological Psychology, 1962, 55, 464-468.

Bliss, D. K. Theoretical explanations of drug-dissociated behaviors. Federation Proceedings, 1974, 33, 1787-1796.

Bloch, S., \& Silva, A. Factors involved in the acquisition of maze habit, analyzed by means of tranquilizing and sedative drugs. Journal of Comparative and Physiological Psychology, 1959, 52, 550-554.
Brown, A., Feldman, R. S., \& Moore, J. W. Conditional discrimination learning based on chlordiazepoxide: Dissociation or cue? Journal of Comparative and Physiological Psychology, 1968, 66, 211-215.

ColpaERT, F. C. Some properties of drugs as physiological signals: The FR procedure and signal detection theory. In F. A. Colpaert \& J. A. Roscrans (Eds.), Stimulus properties of drugs: Ten vears of progress. Amsterdam: Elsevier/North-Holland, 1978.

Doty, R. W., Rutledge, L. T., \& Larsen, R. M. Conditioned reflexes established to electrical stimulation of cat cerebral cortex. Journal of Neurophysiologv, 1956, 19, 401-415.

Gill, J. H., \& NiElson, H. C. State-dependent dissociation of food consumption and maze running in rats. Physiological Psychology, 1978, 6, 179-186.

Gross, C. G., \& Weiskrantz, L. The effect of two "tranquilizers" on auditory discrimination and delayed response performance of monkeys. Quarterly Journal of Studies on Alcohol, 1961, 13, 34-37.

JacoBs, B. L., \& FAREL, P. B. Motivated behaviors produced by increased arousal in the presence of goal objects. Physiology \& Behavior, 1971, 6, 473-476.

Marśhall, J. F., Turner, B. H., \& Teitelbaum, P. Sensory neglect produced by lateral hypothalamic damage. Science, 1971, 174, 523-525.

Modrow, H. E., Petroff, K. S. R., \& Bliss, D. K. Physiological substrates of state-dependent learning. In F. C. Colpaert \& J. A. Roscrans (Eds.), Stimulus properties of drugs: Ten years of progress. Amsterdam: Elsevier/North-Holland, 1978.

Nielson, H. C., Knight, J. M., \& Porter, P. B. Subcortical conditioning, generalization, and transfer. Journal of Comparative and Physiological Psychology, 1962, 55, 168-173.

OTIS, L. S. Dissociation and recovery of a response learned under the influence of chlorpromazine or saline. Science, 1964, $143,1347$.

Overton, D. A. Commentary. In J. A. Harver (Ed.), Behavioral analysis of drug action. Glenview, Ill: Scott, Foresman, 1971. (a)

Overton, D. A. Stimulus control of behavior by drug states. In T. Thompson \& R. Pickens (Eds.), Stimulus properties of drugs. New York: Appleton-Century-Crofts, 1971. (b)

Pusakulich, R. L., \& Nielson, H. C. Neural thresholds and state-dependent learning. Experimental Neurology, 1972, 34, 33-44.

Pusakulich, R. L., \& Nielson, H. C. Cue use in state-dependent learning. Physiological Psychology, 1976, 4, 421-428.

Rutledge, L. T., JR., \& Doty, R. W. Differential action of chlorpromazine on conditioned responses to peripheral versus direct cortical stimulation. Federation Proceedings, 1955, 14, 126.

Sachs, E. Dissociation of learning in rats and its similarities to dissociative states in man. In J. Zubin \& H. Hunt (Eds.), Comparative psychopathology. New York: Grune \& Stratton, 1967.

Schmidt, W., \& Apfelbach, R. Psychopharmakologische Beeinflussung des Beutefangverhaltens beim Frettchen (Putorius furo L.). Psychopharmacology, 1977, 51, 147-152.

Snider, R. S., \& Niemer, W. T. A stereotaxic atlas of the cat brain. Chicago: University of Chicago Press, 1961.

Weiskrantz, L., \& Baltzer, V. A note on further experiments of meprobamate on discrimination performance in the monkey. Quarterly Journal of Experimental Psychology, 1965, 17, 169-172.

Wolgin, D. L., Cytawa, J., \& Teitelbaum, P. The role of activation in the regulation of food intake. In D. Novin, W. Wyrwicka, \& G. Bray (Eds.), Hunger: Basic mechanisms and clinical implications. New York: Raven Press, 1976.

(Received for publication February 11, 1980; revision accepted June 16,1980 .) 